\title{
Further emergent evidence for the vitamin D endocrine system involvement in autoimmune rheumatic disease risk and prognosis
}

\author{
Maurizio Cutolo
}

\section{VITAMIN D: A TRUE ENDOGENOUS IIMIMUNOMIODULATOR}

Recently, vitamin D has received increased worldwide attention for its involvement in reducing risk for several chronic diseases including many cancers, infectious diseases, type 1 diabetes and notably autoimmune rheumatic diseases. ${ }^{1}$

The final active metabolite of vitamin D $\left(1,25(\mathrm{OH}) \mathrm{D}_{3}\right)$ is considered a steroid hormone for its origin from cholesterol (D-hormone), and like glucocorticoids exerts immunomodulatory activities (figure 1). ${ }^{2} 3$

Pathophysiological investigations confirm that severe hypovitaminosis $\mathrm{D}$, in genetically predisposed subjects, can impair self tolerance and immune responses by compromising the regulation of dendritic cells, regulatory T-lymphocytes (Tregs), Th1 cells and B cell function. ${ }^{3}$

Cross-sectional studies have shown that deficient serum levels of vitamin $\mathrm{D}$ $(25(\mathrm{OH}) \mathrm{D})(<20 \mathrm{ng} / \mathrm{ml})$ are present in a significant percentage, not only in patients with autoimmune diseases such as multiple sclerosis (MS), type 1 diabetes, systemic lupus erythematosus (SLE) or rheumatoid arthritis (RA), but also in healthy subjects. ${ }^{4}$ In addition, the presence of severe $25(\mathrm{OH}) \mathrm{D}$ deficiency $(<10 \mathrm{ng} / \mathrm{ml})$ is also involved in the generation of symptoms that characterise patients with rheumatic diseases (ie, musculoskeletal pain in RA), and supplementation seems to induce improvements. $^{67}$

\section{Research Laboratory and Academic Clinical Unit of Rheumatology, Division of Rheumatology, Department of Internal Medicine, University of Genova, Genova, Italy}

Correspondence to Professor Maurizio Cutolo, Research Laboratory and Academic Clinical Unit of Rheumatology, Division of Rheumatology, Department of Internal Medicine, University of Genova, Viale Benedetto, XV, 6, Genova, Italy;mcutolo@unige.it

\section{VITAMIN D DEFICIENCY, \\ AUTOANTIBODY INDUCTION AND IDIOPATHIC INFLAMIMATORY \\ MYOPATHIES}

Azali et al report significant vitamin D deficiency in patients with idiopathic inflammatory myopathies (IIM)-polymyositis, dermatomyositis (DM), inclusion body myositis-compared to a gender matched control population and based on samples collected during the same months of the year. ${ }^{8}$

The IIM patients with shorter disease duration showed lower levels of serum 25 $(\mathrm{OH}) \mathrm{D}$ than those with established treated disease, supporting the hypothesis that low levels of vitamin $\mathrm{D}$ could be at least one of several risk factors in development of IIM, as already assessed in MS, RA and SLE.

The suggested role for low serum 25 $(\mathrm{OH}) \mathrm{D}$ as a risk factor in autoimmunity seems strongly reinforced by some recent investigations showing that even antinuclear antibodies (ANA)-positive healthy controls are significantly more likely to be deficient in vitamin $\mathrm{D}$ serum levels than ANA-negative healthy controls. ${ }^{9}$ Conversely, in a recent survey, vitamin D supplementation (140 000 IU at baseline and after 4 weeks) was found to be associated with significant increases of Tregs frequency (\%Tregs) in apparently healthy individuals. ${ }^{10}$

Interestingly, a significantly higher frequency of autoantibodies (anti-Jo-1) was also found by Azali et al in IIM patients who had significantly lower median serum 25(OH)D levels compared to controls. ${ }^{8}$

In addition to the finding that vitamin $\mathrm{D}$ deficiency is associated in SLE patients with certain immune abnormalities and significantly correlates in a negative manner with clinical SLE activity and anti-dsDNA titre, it is strongly suggested that vitamin $\mathrm{D}$ deficiency plays an important role in enhancing autoantibody production. ${ }^{11}$
Interestingly, in an interventional study evaluating the immunological effects of vitamin $\mathrm{D}$ supplementation in 20 SLE patients with hypovitaminosis $\mathrm{D}, \quad \mathrm{a}$ decrease of memory $B$ cells and anti-DNA antibodies together with a preferential increase of naive CD4 T cells, an increase of regulatory $T$ cells and a decrease of effector Th1 and Th17 cells were observed. ${ }^{12}$

Furthermore, a very recent study showed that reduced serum 25(OH)D levels are associated with the presence of autoimmune response in tuberculosis patients, by reporting a significant negative correlation between the titres of the ANA and the serum levels of $25(\mathrm{OH}) \mathrm{D} .{ }^{13}$

A new and intriguing study links low serum $25(\mathrm{OH}) \mathrm{D}$ and elevated immunoreactivity against Epstein-Barr virus (EBV) in 25 individuals who had donated blood prior to the first clinical MS manifestation (clinically isolated syndrome). ${ }^{14}$ In fact, a novel role for low vitamin $\mathrm{D}$ as risk factor and/or modifier of autoimmune response is introduced. It is proposed that deprivation of solar light or low serum $25(\mathrm{OH})$ $\mathrm{D}$ at higher latitudes, facilitates the development of autoimmune diseases by aggravating the CD8 T-cell deficiency, thereby further impairing control of EBV and permitting clonal expansion of autoreactive $B$ cells infected with EBV. ${ }^{15}$

\section{A LESSON FROM VITAMIN D AND CHRONIC INFECTIONS/ INFLAMIMATION: THE CASE OF TUBERCULOSIS}

Vitamin D is synthesised at an increased rate inside monocytes/macrophages in the presence of bacterial and viral infections, and in normal conditions stimulates the synthesis of antimicrobial peptides such as cathelicidins, which contribute to bacterial killing and defence against pathogens (such as Mycobacterium tuberculosis). ${ }^{3}$

These mechanisms support the beneficial therapeutic effects exerted by graded solar light exposure, which was used to treat chronic tuberculosis in the so called 'sanatoria' at the beginning of the twentieth century.

In addition, a systematic review of the period between 1971 and 2006 in 11 countries and regions from around the world confirmed a seasonal pattern for tuberculosis, with the most prominent peak during the winter and spring seasons (the time of the circannual reduction in vitamin $\mathrm{D}$ synthesis) in all of the countries studied. ${ }^{16} 17$

Recently, 95 patients receiving antimicrobial therapy for pulmonary tuberculosis who were randomised to receive adjunctive high-dose vitamin D or placebo in a clinical trial, and who fulfilled criteria for per- 


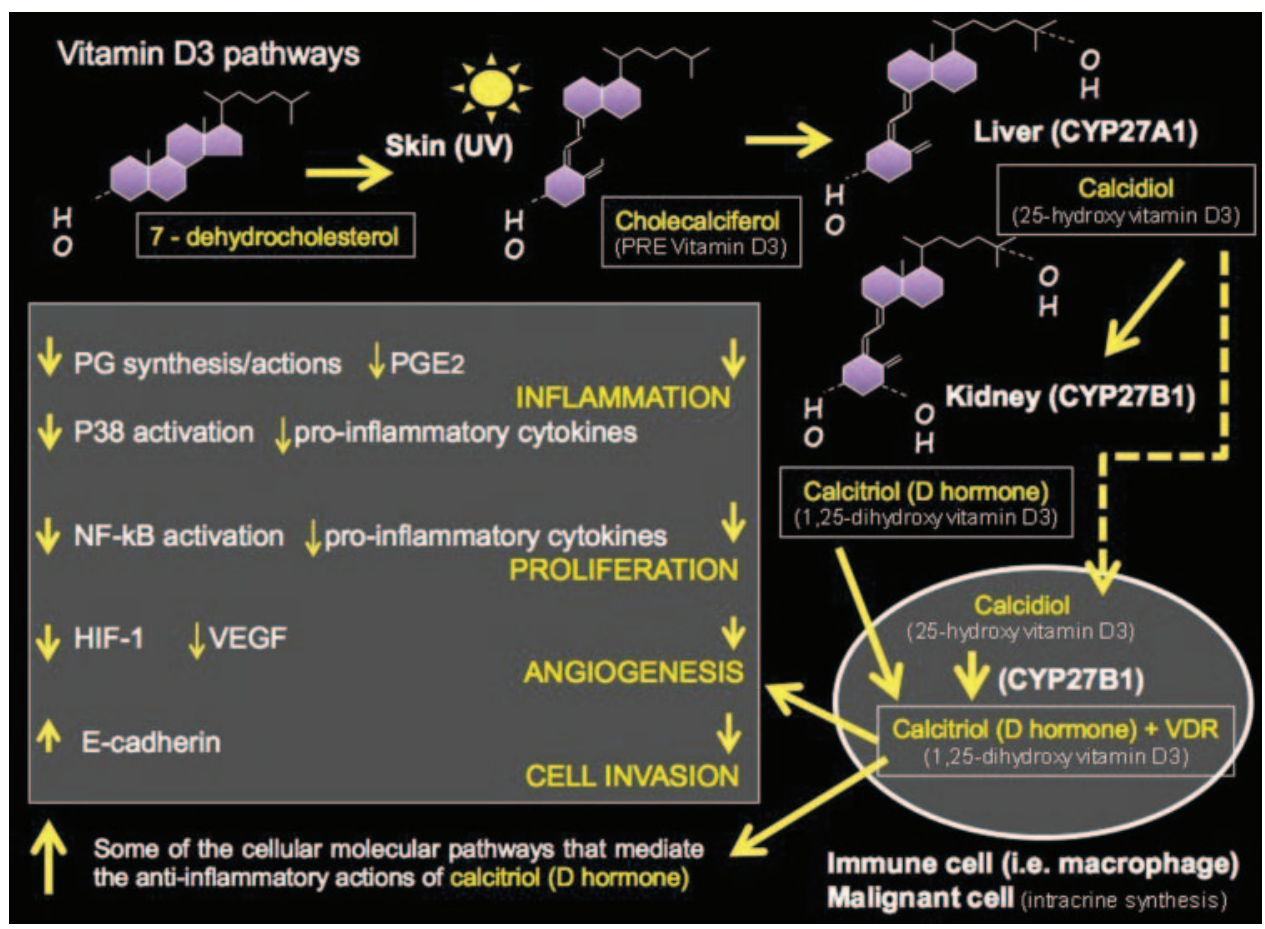

Figure 1 Newly identified target genes for calcitriol (D hormone) reveal multiple molecular pathways of anti-inflammatory actions for $1,25(\mathrm{OH}) \mathrm{D}_{3}$ in several cell types. These include: inhibition of prostaglandin (PG) synthesis and biological actions; inhibition of p38 stress kinase activation and production of proinflammatory cytokines such as IL-6 (via induction of MAP kinase phosphatase 5 (MKP5 expression); inhibition of nuclear factor $\kappa B$ (NF- $\kappa B$ ) signalling which results in the attenuation of the synthesis of proinflammatory cytokines such as interleukin-8 (IL-8) (via up-regulation of the expression of insulin-like growth factor binding protein-3 (IGFBP-3); inhibition of angiogenesis due to suppressive effects on the expression of proangiogenic factors such as hypoxia-inducible factor 1 (HIF-1) and vascular endothelial growth factor; increase in the expression of E-cadherin, leading to the inhibition of invasion and metastasis. Solid lines indicate direct actions of calcitriol, and dotted lines indicate downstream effects of calcitriol.

protocol analysis, also showed an accelerated resolution of inflammatory responses during tuberculosis treatment. ${ }^{18}$

The administration of vitamin D enhanced the treatment-induced suppression of antigen-stimulated Th1 cytokine responses and is a further lesson on the previously unrecognised anti-inflammatory activities exerted by $1,25(\mathrm{OH}) \mathrm{D}_{3}$.

\section{SOLAR LIGHT, VITAMIN D AVAILABILITY AND RA RISK}

Linked to the different seasonal vitamin $\mathrm{D}$ availability, recent studies have shown that people living at the highest latitudes have a higher risk of RA, especially in winter, which may be due to lower ultraviolet (UV) light exposure. ${ }^{19} 20$ In fact, the UV light may suppress autoimmunity and thus may decrease the risk of RA.

The very recent study by Arkema et al, investigating the association between UV-B light exposure and risk of RA among women in two large prospective cohort studies (the Nurses' Health Study (NHS) and the NHSII) confirmed a significant decreased RA risk with higher UV-B exposure, in particular in the absence of sun-protective behaviours. ${ }^{21}$

Interestingly, 1314 incident RA cases were identified in total and among NHS participants, higher cumulative average UV-B exposure was associated with decreased RA risk; those in the highest versus lowest category had a $21 \%$ decreased RA risk (HR 0.79, 95\% CI 0.66 to 0.94).

These results confirm the conclusions of another recent large cohort study, which showed that besides the usual initial biomarkers that have been associated with the progression of early RA, the season of symptom onset (ie, winter or spring) acts as an independent predictive factor for the progression of joint structural damage at 6 months. $^{22}$ Furthermore, the onset of symptoms of early RA during winter or spring was also associated with greater radiographic evidence of disease progression at 12 months. ${ }^{22}$

Adding weight to these findings, multivariate analysis produced the same results in two adjoining seasons (winter and spring, summer and autumn), and at both 6 and 12 months, suggesting a clear role for solar light/vitamin D implication. ${ }^{22} 23$

On the other hand, if infections represent one of the risk factors (trigger factors) for the development of early RA (and generally autoimmune diseases), the seasonality of the onset and severity of RA might also be linked to the seasonality of infections and associated vitamin $\mathrm{D}$ deficiency, as previously discussed. ${ }^{24}$

Accordingly, abnormally large seasonal declines in vitamin $\mathrm{D}$ status (deficiency) may also trigger flares in patients with
SLE. $^{25}$ A recent investigation in non-Afro-American SLE patients showed that unusually large declines in vitamin $\mathrm{D}$ during low daylight months (OctoberMarch) may be mechanistically related to SLE flare, whereas relatively high vitamin D levels during high daylight months (JulyAugust) may protect against flares. ${ }^{25}$

As mentioned above, vitamin D supplementation in SLE patients with hypovitaminosis $\mathrm{D}$ induced a decrease of memory $\mathrm{B}$ cells and anti-DNA antibodies, together with a preferential increase of naive CD4 $\mathrm{T}$ cells, an increase of regulatory $\mathrm{T}$ cells and a decrease of effector Th1 and Th17 cells. ${ }^{11}$

Interestingly, a recent clinical study assessed that a significant solar-induced $\Delta 25(\mathrm{OH}) \mathrm{D}$ was present at the earliest on 8 April, maximal by early August and decreased by late August, following the availability of efficient UV light doses. ${ }^{26}$

All this clinical and epidemiological evidence seems in agreement with several experimental studies, showing that UV radiation acts as an immunosuppressant by up-regulating Th2 cells, downregulating Th1 cells, and inducing the production of interleukin-10 and $T$ regulatory cells. ${ }^{27} 28$ UV-B exposure (solar light) could thus decrease the risk of RA onset as well as relapses, through increasing serum vitamin $D$, which exerts known immunomodulatory effects. ${ }^{29}$ 
EMERGENT EVIDENCE: VITAMIN D DEFICIENCY AND AROMATASES IN RA AND CANCER

A prominent endocrine role for $1,25(\mathrm{OH}) \mathrm{D}_{3}$ was recently discovered in peripheral oestrogen metabolism and in oestrogen-related cell proliferative activities. $1,25(\mathrm{OH}) \mathrm{D}_{3}$ decreases the expression of aromatase, the enzyme that generally catalyses the peripheral synthesis of oestrogens from androgens, especially in cancer tissues where its intracrine activity is significantly increased, such as in breast and prostate cancer. ${ }^{30}$

Similar inhibitory effects by $1,25(\mathrm{OH}) \mathrm{D}_{3}$ have been recently reported on cultures of human macrophages with consequent reduced synthesis of cytokines. ${ }^{31} 32$ Inflammatory cytokines (tumour necrosis factor- $\alpha$, interleukins 6 and 1) are strong enhancers of aromatase activity, as observed in chronic inflammatory conditions such as RA synovitis or SLE skin. ${ }^{33}{ }^{34}$ As a consequence, oestrogen metabolite synthesis is increased in synovial fluids of both male and female RA patients and seem involved in synovial cell proliferation. ${ }^{35}$

Interestingly, $1,25(\mathrm{OH}) \mathrm{D}_{3}$ exerts an inhibitory effect by a direct repression of aromatase transcription via promoter II, as well as an indirect effect due to a reduction in the levels and biological activity of prostaglandins (especially PGE2), which are a major stimulator of aromatase transcription through promoter II. ${ }^{36}$

Aromatase inhibitors used in breast cancer treatment inhibit the enzymatic activity, while $1,25(\mathrm{OH}) \mathrm{D}_{3}$ reduces aromatase expression. Recently, an enhanced growth inhibitory effect by combining $1,25(\mathrm{OH}) \mathrm{D}_{3}$ and aromatase inhibitors in breast cancer cell cultures was revealed. ${ }^{37}$

The higher incidence of autoimmune rheumatic diseases in women also seems supported by possible links between vitamin $\mathrm{D}$ deficiency (with reduced down-regulation of aromatases), increased synthesis of peripheral oestrogens and increased risk/severity for RA, as already proposed in different types of cancer. ${ }^{37} 38$

\section{CONCLUSIONS}

Evidence supports an increased risk for autoimmune diseases, as well as for infections and cancer, in vitamin $\mathrm{D}$ deficiency. In the presence of overt disease, the severity of the process seems related to vitamin $\mathrm{D}$ deficiency. The link between the seasonality of $1,25(\mathrm{OH}) \mathrm{D}_{3}$ deficiency and the circannual incidence and severity of at least some autoimmune rheumatic disorders, might be reduced by its therapeutic supplementation.

\section{Competing interests None}

Provenance and peer review Commissioned; externally peer reviewed.
Correction notice This paper has been corrected since it was published Online First. A new version of Figure 1 has replaced a previous incorrect version.

Received 27 October 2012

Accepted 1 January 2013

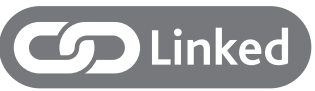

- http://dx.doi.org/10.1136/annrheumdis-2012-201849

- http://dx.doi.org/10.1136/annrheumdis-2012-202302

Ann Rheum Dis 2013;72:473-475.

doi:10.1136/annrheumdis-2012-202538

\section{REFERENCES}

1. Holick MF. Evidence-based D-bate on health benefits of vitamin D revisited. Dermatoendocrino/ 2012;4:183-90

2. Cutolo M, Pizzorni C, Sulli A. Vitamin D endocrine system involvement in autoimmune rheumatic diseases. Autoimmun Rev 2011;11:84-7.

3. Cutolo M, Plebani M, Shoenfeld Y, et al. Vitamin D endocrine system and the immune response in rheumatic diseases.. Vitam Horm 2011;86:327-51.

4. Cantorna MT, Mahon BD. Mounting evidence for vitamin $\mathrm{D}$ as an environmental factor affecting autoimmune disease prevalence. Exp Biol Med (Maywood) 2004;229:1136-42.

5. Cutolo M, Otsa K, Paolino S, et al. Vitamin D involvement in rheumatoid arthritis and systemic lupus erythaematosus. Ann Rheum Dis 2009;68:446-7.

6. Haque UJ, Bartlett SJ. Relationships among vitamin D, disease activity, pain and disability in rheumatoid arthritis. Clin Exp Rheumatol 2010;28:745-7.

7. Gopinath K, Danda D. Supplementation of 1,25 dihydroxy vitamin D3 in patients with treatment naive early rheumatoid arthritis: a randomised controlled trial. Int J Rheum Dis 2011;14:332-9.

8. Azali P, Barbasso Helmers S, Kockum I, et al. Low serum levels of vitamin $D$ in idiopathic inflammatory myopathies. Ann Rheum Dis 2013;72:512-6.

9. Ritterhouse LL, Crowe SR, Niewold TB, et al. Vitamin $D$ deficiency is associated with an increased autoimmune response in healthy individuals and in patients with systemic lupus erythematosus. Ann Rheum Dis 2011;70:1569-74.

10. Prietl B, Pilz S, Wolf M, et al. Vitamin D supplementation and regulatory T cells in apparently healthy subjects: vitamin $\mathrm{D}$ treatment for autoimmune diseases? Isr Med Assoc J 2010;12:136-9.

11. Mok CC, Birmingham DJ, Ho LY, et al. Vitamin D deficiency as marker for disease activity and damage in systemic lupus erythematosus: a comparison with anti-dsDNA and anti-C1q. Lupus 2012;21:36-42.

12. Terrier B, Derian N, Schoindre $\mathrm{Y}$, et al. Restoration of regulatory and effector T cell balance and B cell homeostasis in systemic lupus erythematosus patients through vitamin $\mathrm{D}$ supplementation. Arthritis Res Ther 2012;14:R22.

13. Li Wenli, Zhang Rui, Zhang Kuo, et al. Reduced vitamin D levels are associated with autoimmune response in tuberculosis patients. Ann Rheum Dis 2012;71:790.

14. Décard BF, von Ahsen N, Grunwald T, et al. Low vitamin $D$ and elevated immunoreactivity against Epstein-Barr virus before first clinical manifestation of multiple sclerosis. J Neurol Neurosurg Psychiatry 2012;83:1170-3.

15. Pender MP. CD8+ T-Cell Deficiency, Epstein-Barr virus infection, vitamin $D$ deficiency, and steps to autoimmunity: a unifying hypothesis. Autoimmune Dis 2012;2012:189096.

16. Fares A. Seasonality of tubercolosis. J Glob Infect Dis 2011;3:46-55.

17. Realegeno S, Modlin RL. Shedding light on the vitamin D-tuberculosis-HIV connection. Proc Natl Acad Sci USA 2011;108:18861-2.
18. Coussens AK, Wilkinson RJ, Hanifa Y, et al. Vitamin $\mathrm{D}$ accelerates resolution of inflammatory responses during tuberculosis treatment. Proc Natl Acad Sci USA 2012;109:15449-54

19. Cutolo M, Otsa K, Laas K, et al. Circannual vitamin $D$ serum levels and disease activity in rheumatoid arthritis: Northern versus Southern Europe. Clin Exp Rheumatol 2006;24:702-4.

20. Costenbader $\mathbf{K H}$, Chang SC, Laden F, et al. Geographic variation in rheumatoid arthritis incidence among women in the United States. Arch Intern Med 2008;168:1664-70.

21. Arkema EV, Hart JE, Bertrand KA, et al. Exposure to Ultraviolet-B and risk of developing rheumatoid arthritis among women in the Nurses' Health Study. Ann Rheum Dis 2013;72:506-11.

22. Mouterde G, Lukas C, Logeart I, et al. Predictors of radiographic progression in the ESPOIR cohort: the season of first symptoms may influence the short-term outcome in early arthritis. Ann Rheum Dis 2011;70:1251-6.

23. Cutolo M. Rheumatoid arthritis: circadian and circannual rhythms in RA. Nat Rev Rheumatol 2011;7:500-2.

24. Zittermann A. Vitamin D in preventive medicine: are we ignoring the evidence? Br J Nutr 2003;89:552-72.

25. Birmingham DJ, Hebert LA, Song $H$, et al. Evidence that abnormally large seasonal declines in vitamin D status may trigger SLE flare in non-African Americans. Lupus 2012;21:855-64.

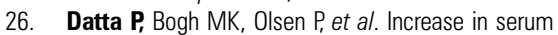
25-hydroxyvitamin-D(3) in humans after solar exposure under natural conditions compared to artificial UVB exposure of hands and face. Photochem Photobiol Sci 2012;11:1817-24.

27. Aubin F. Mechanisms involved in ultraviolet lightinduced immunosuppression. Eur J Dermatol, 2003;13:515-23.

28. Norval M. Effects of solar radiation on the human immune system. J Photochem Photobiol 2001;63 28-40.

29. Cutolo M. Solar light effects on onset/relapses and circannual/circadian symptomatology in rheumatoid arthritis. Clin Exp Rheumatol 2003;21:148-50.

30. Sasano H, Miki Y, Nagasaki S, et al. In situ estrogen production and its regulation in human breast carcinoma: from endocrinology to intracrinology. Pathol Int 2009;59:777-89.

31. Villaggio B, Soldano S, Cutolo M. Vitamin D modulates aromatase expression in human macrophages and downregulates proinflammatory cytokine production via ERK/MAPK signaling. Ann Rheum Dis 2012;71(suppl 1):A75.

32. Villaggio $\mathbf{B}$, Soldano $\mathrm{S}$, Cutolo $\mathrm{M}$ 1,25-dihydroxyvitamin D3 downregulates aromatase expression and inflammatory cytokines in human macrophages. Clin Exp Rheumatol 2012;30: 934-8.

33. Cutolo M, Sulli A, Straub RH. Estrogen metabolism and autoimmunity. Autoimmun Rev 2012;11 A460-4.

34. Folomeev M, Dougados M, Beaune J, et al. Plasma sex hormones and aromatase activity in tissues of patients with systemic lupus erythematosus. Lupus 1992;1:191-5

35. Capellino S, Montagna P, Villaggio B, et al. Hydroxylated estrogen metabolites influence the proliferation of cultured human monocytes: possible role in synovial tissue hyperplasia. Clin Exp Rheumatol 2008;26:903-9.

36. Cutolo $\mathbf{M}$. The challenges of using vitamin $D$ in cancer prevention and prognosis. Isr Med Assoc J 2012;14:637-9.

37. Krishnan AV, Swami S, Peng L, et al. Tissue-selective regulation of aromatase expression by calcitriol: implications for breast cancer therapy. Endocrinology 2010;5:32-4.

38. Bosland MC, Mahmoud AM. Hormones and prostate carcinogenesis: androgens and estrogens. J Carcinog 2011;10:33-7. 